\title{
DE LA ESPROPIACIÓN POR LA CAUSA DE UTILIDAD PÚBLICA
}

\author{
Juvenal Hernández Jaque
}

* Imprenta Comercial. Santiago. 1923. Colección Tesis. Biblioteca Central de la Facultad de Derecho. Universidad de Chile. 



\section{Juvenal Hernández J.}

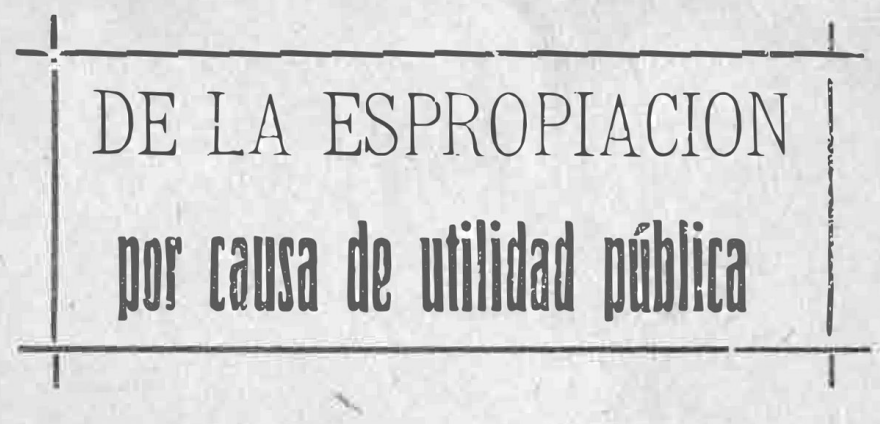

Memoria de pruetus para pylar al grado de Licenciarlo en lis firrullad de Leyes i Ciencias Politicas de la Universidad de Chile.
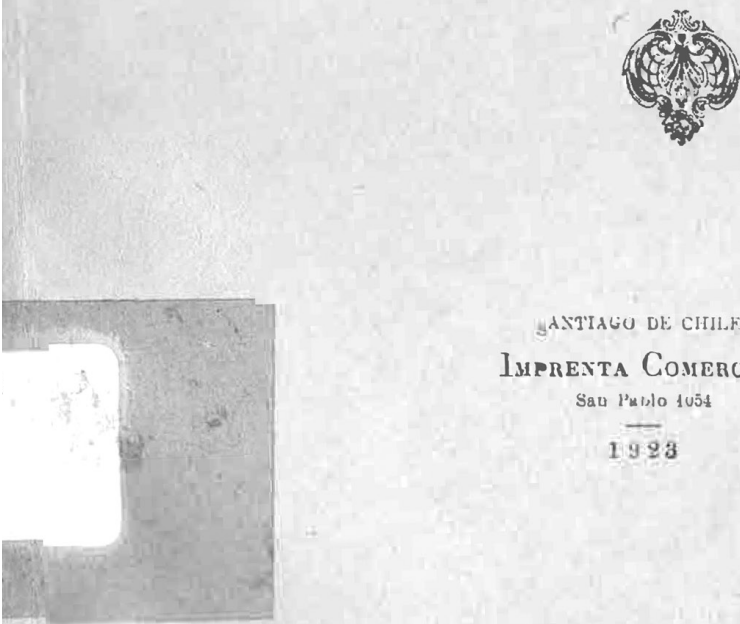

SAITIAGU DE CHILF

Imprenta Comercial

Sau l'uslo tu5t

$1 \overline{993}$ 
progreso i la armonía social, que són también el fin supremo del Estado mismo.

\section{GAPITULO III}

\section{Requisitos fara que proceda la espropiación}

En el curso de los capítulos anteriores, hemos podido ver que la espropiación procede, i esto ateniéndonos a lo estatuido en las lejislaciones de todos los pueblos civilizados, sólo cuando concurren estos tres requisitos: utilidad pública; declaración de ella, i justa i previa indemnizaciórr. Veremos separadamente cada uno de estos requsitos:

1. ¿Qué se entiende por utilidad públicậ... Ninguna lei ha podido definirla, ni mucho menos los numerosos tratadistas de Derecho Administrativo. Tampoco creemos que pueda darse una definición.

Porque, í hai algo más elástico que el concepto de utilidad? .. Ella se manifiesta bajo los aspectos más diversos: un fín económico, que tenga por objeto el mayor desarrollo de una esplotación nacional; un fín financiero, que deba procurar recursos al erario; un fín de seguridad nacional, como seriå la construcción de un ferrocarril; un fín sccial, edilicio, judicial, etc.. reune en sí el carácter de utilidad pública tanto como un fin moral, intelectual o de beneficencia. Ultimamente se ha ampliado tauto la estensión del concepto utilidad, que se ha comprendido en él hasta los fines de ornato i recreo de las poblaciones. Con mayor razón, por cierto, los tines de salubridad, habiéndose presentado casos, como el contemplado por la lei de 4 de Febrero de 1915 en Francia, que autorizan la espropiación de habitaciones declaradas insalubres por las correspondientes inspecciones de hijiene.

La noción amplia de utilidad pública, comprende todos los descubrimientos i progresos de la ciencia, cualquiera que sea la naturaleza de esta, i responde a todas las necesidades materiales, morales i aún artísticas de una nación. De aquí le infiere que el poder público Ilamado por la lei a declarar su utilidad, goza de un campo ilimitado para apreciarla, sin 
que sea posible ni fijar normas aproximadas, puesto que la constante evolución de las cosas i de las ideas lleva cousigo la relatividad de todos los conceptos.

Al tratar este punto no debemos olvidar que el concepto de utilidad pública data sólo desde los primeros años del siglo XIX, época en que el Código de Napoleón lo introdujo en reemplazo de la exijencia de necesidad pública que antes contemplaban todas las lejislaciones, como veremos en el capítulo siguiente. Las ventajas del cambio resaltan a primera vista.

A menudo ha sido confundida la utilidad pública con la utilidad fiscal o del Estado. Sin embargo, la primer a puede existir separadamente $i$ sin que existan las otras.

Así, por ejemplo, sería una obra de utilidad pública la construcción de un ferrocarril, ya que este beneficiaría a la sociedad entera; i sería obra de utilidad fiscal la construcción o esplotación de $n$ establesimiento industrial que produjera utilidades al Fisco.

Veames lo que dice sobre el particular don Alcibiades Roldán en su obra «Elementos de Derecho (ionstitucioral». *No debe confundirse-dice-la uliliilad del Estado con la utilidad del Fisco. Esta última no bastaría para justificar una espropiación. Si es respetable el interes liscal, to es no en menor grado el derecho de los particulares. Así, podría signilicar un negocio para el Fisco espropiar un establecimiento industrial o mercantil, pero atendida la recta interpretación del proyecto constitucional, esta sola circunstancia no justificaría una espropiaciónn.

No hai que olvidar que el número 5.o del articulo 10 de nuestra Constitución habla de utilidad del Estado, con lo que se quizo talvez dar mayor ainplitud a la facultad de espropiar; pero posteriormente se ba declarado, como veremos, que la utilidad del Estado es la misma utilidad pública. Por otra parte, no puede desconocerse que la base lójica i natural de la espropiación debe ser la utilidad pública i que si se interpretara a la letra el precepto constitucional, ello se prestaría a abusos que llevarían a violar injustamente el derecho de propiedad. 
Por su parte, don Jorje Huneeus, en su obra «La Constitución ante el Congreso», se pronuncia en este mismo sentido.

Ha dado también ocasión a innumerables controversias la cuestión relativa a saber si la utilidad pública debe ser directa o indirecta o bién mediata o inmediata. Nos atrevemos a afimar que todas estas especies de utilidad autorizan el procadimiento de espropiación, ya que siendo el Estado un sujeto de duración ilimitada, es justo que tenga en vista el interés de las jeneraciones futuras, tanto o más que el de las presentes, i ya que, sea la utilidad directa o indirecta, ambas se traducen en una forma de bienestar colectivo.

Por considerarlo de interés, citaremos aquí un informe espedido el año 72 por una comisión lejislativa $i$ comentado por don Jorje Huneeus en su obra anteriormente citada. «La utilidad del Estado-dice el referido informe-çse encuentra solamente en aquello que aprovecha a toda la comunidad nacional, a todas las localidades de la República. i que les aprovecha de un modo directo e indirecto?... En tal caso, podría asegurarse que ninguna de las espropiaciones autorizadas por nuestros diversos Congresos ha sido constítucional. Las espropiaciones mas frecuentes, las que autori. zan para la construcción de ferrocarriles no lo habrían sido casi nunca, pués una via férrea no beneficia, en la mayor parte de los casos, sino a una porción mas o menos reducida de nuestro territorio."

La utilidad pública es, pués, el único motivo por el que el Derecho autoriza a posponer el interés privado ante el interés público. I esta es, como hemos visło, la razón jurídico-filosófica en que se apoya la espropiación.

Se produce aquí un conflicto entre el Estado, sujeto de Derecho público, que necesita de medios para poder subsistir i cumplir sus fines i el propietario particular que posee la finca o el bien necesario para satisfacer ese fin. Ahora bien: siendo el Derecho la fuevza reguladora de los intereses de los iudividuos que forman el grupo social, es a él a quien corresponde resólver este conflicto sin inclinarse a uno u otro lado, esto es, sin avanzarse al campo del socialismo ni 
entrar tampoco al del individualismo. Entonces, ¡icómo proceder para no violar la esfera de la propiedad individual?... Transformado el patrimonio de las personas por medio de la espropiación por causa de utilidad pública.

Siguiendo nuestro análisis del primer requisito exijido para que la espropiación tenga lugar, cabe preguntar ¿qué requisitos debe reunir la utilidad pública?. Sintetizando la opinión de algunos autores como Posada, Santamaria, Soler i otros, estos requisitos serían los siguientes:

a) Debe ser evidente;

b) Debe ser impersonal:

c) Debe estar representada por usos i aprovechamientos comunes que miren a la prosperidad jeneral.

$Y$ a hemos visto que no importa que el beneficio sea indirecto, pués lo esencial es que haya bienestar jeneral. Tampoco debe olvidarse que la utilidad pública puede perseguir, como objetivos, tanto el uso como la propiedad de los bienes.

2.o El segundo requisito que se exije para que proceda la espropiación es que la utilidad pública sea declarada por un poder suficiente, requisito que se justifica por sí sólo si se considera que la propiedad es inviolable i que sólo en casos estremos, como es el de la espropiación, puede limitarse.

¿Quién debe declarar la utilidad pública? .. El criterio para apreciar este punto ha sido diverso en casi todas las lejislaciones. Algunas, i entre ellas la nuestra. han establecido que sea el poder lejislativo, por medio de una lei, el que declare la utilidad pública; i otras, por el contrario. estatuyen que la espropiación puede ser a veces materia de decreto, sobre todo cuando la naturaleza de la obra así lo requiere. Las lejislaciones de Francia, Italia, España, Béljica i Prusia exijen sólo en ciertos casos la lei: cuando se trata de obra de menor trascendencia o simplemente rejionales, basta un decreto de la autoridad administrativa correspondiente. En Inglaterra i Rusia se exije en todo caso una lei.

Las lejislaciones que aceplan el decreto se basan en que 
la espropiación no es jamás un procedimiento en que intervenga la política, sino que, por el contrario, es i debe ser siempre una institución de carácter netamente administrativo, que cae por completo dentro del campo de acción del poder ejecutivo que, como sabemos, es el que tiene el predominio de la potestad reglamentaria.

A esto podría objetarse, sin embargo, que la declaración de utilidad pública sirve de antecedente a un aclo que menoscaba uno de los derechos individuales, que importa una limitación a la libertad de las personas, i, por consiguiente, sólo puede ser materia de una lei.

De aquí que la mayoría de los paises han optado por una solución intermediaria, atribuyendo la competencia para declarar la utilidad pública tanto a la lei como al decreto, según sea la naturaleza o importancia de la obra que se trata de construír.

3.o Si el Estado, so pretesto de que el interés público lo exije, pudiera privar a una persona de su propiedad sin otorgarle compensación alguna, se cometería lisa illanamente un despojo, un despojo por demás irritante e imperdonable desde que se haría en nombre del Derecho, del cual es el Estado depositario.

$\mathrm{Ni}$ aún dentro de las antiguas escuelas de gohierno, que se inspiraban en ideas como aquella de que (no hai derecho superior al Derecho mismo». o de que (el Estado. que es una persona moral, no puede hacer daño a nadiem, tendría justificación un procedimiento semejante.

Por esto, i en atención al mismo concepto que hoi día se tiene de las relaciones entre el Estado i los individuos, las diversas lejislaciones establecen que cuando, por exijirlo el bienestar público, haya necesidad de recurrir al procedimiento estraordinario de espropiación, esto es, a una enaje. nación forzada, el Estado. en nombre de la sociedad, que es la que resulta favorecida, indemnice al propietario el justo valor de su propiedad. Desaparece por este medio el carácter de despojo arbitrario que podría tener la iustitución, para ser, por el contrario una especie de cambio de 
dominio; se sustituye el dominio ejercido sobre el bien espropiado por el que se adquiere sobre la suma convenida como indemnización,

Cómo se calcula la indemnización?... Este es, precisamente, el punto de mayor reglanentación en todos los paises, ya que no siempre suele ser fácil determinar en un momento dado el valor de uni cosa i ya que la valoración practicala dejará siempre descontenta a una de las partes.

Para conseguir determinar el justiprecio del bién espropiado se han ideado medios como el de la institución del jurado de hombres buen'ss o el diclámen de peritos, con intervención de la autoridad judicial o administrativa cuando no se produce acuerdo.

Todas las lejislaciones establecen que la indemnización debe ser prévia. De aquí que la espropiación no se consume hasta que no se haya hecho el pago, i el espropianta no tiene la posesión legal del bién mientras este no se haya verificado.

En la determinación del justiprecio se presentan algunos problemas de inás o menos importancia, de los cuales no ocuparemos en detalle al tratar el punto en el estudio que mas adelante haremos de muestra lejislación positiva.

\section{CAPITULO IV}

\section{Reseṽa Histónica ur ua Espropiación}

1. La institución de Drecho Público conocida con el nombre de espropiación ha sido practicada deste los tiempos mas remotos. Su orijen se remonta casi a los orijines misinos del derecho de propiedad, ya que siendo este una consecuencia iameliata de las necesidades sociales, tiene, entre otros fines, el de proveer a aquella que está representada por la utilidad común, por la necesidad colectiva.

En efecto, en la Biblia misina, que fité, como sabemos, ura enciclopedia en que se contenía desde el más simple consejo de hijiene individual hasta las más complejas reglas de Moral i de Derecho, encontramos reconocida i practicada la espropiación por los Hebreos. El versículo 23 del capítulo 21 del libro $1 .^{\circ}$ de las Crónicas refiere que un ánjel, 